\title{
Quick Preparative Separation of Natural Naphthopyranones with Antioxidant Activity by High-Speed Counter-Current Chromatography
}

\author{
Gilda G. Leitão $\mathrm{a}^{\mathrm{a}}$, Suzana G. Leitão $\mathrm{o}^{\mathrm{b}}$ and Wagner Vilegas $\mathrm{c}^{\mathrm{c}^{*}}$
}

a Núcleo de Pesquisas de Produtos Naturais, UFRJ, Rio de Janeiro, RJ, Brazil

b Faculdade de Farmácia, Depto. de Produtos Naturais e Alimentos, UFRJ, Rio de Janeiro, RJ, Brazil

c Instituto de Química de Araraquara, UNESP, Depto. de Química Orgânica, CP 355, 14801-1970, Araraquara, SP, Brazil. Fax: +55-16-222-7932. E-mail: vilegasw@iq.unesp.br

* Autor for correspondence and reprint requests

Z. Naturforsch 57c, 1051-1055 (2002); received June 4/July 2, 2002

High-Speed Counter-Current Chromatography, Naphthopyranone Glycosides, Antioxidant Activity

The natural naphthopyranones paepalantine (1), paepalantine- $9 O-\beta$-D-glucopyranoside (2) and paepalantine-9- $O$ - $\beta$-D-allopyranosyl- $(1 \rightarrow 6)-O$ - $\beta$-D-glucopyranoside $(\mathbf{3})$ were separated in a preparative scale from the ethanolic extract of the capitula of Paepalanthus bromelioides by high-speed counter-current chromatography (HSCCC). The solvent system used was composed of water-ethanol-ethyl acetate-hexane $(10: 4: 10: 4, \mathrm{v} / \mathrm{v} / \mathrm{v} / \mathrm{v})$. This technique led to the separation of the three different naphthopyranone glycosides in pure form in approximately 7 hours. Paepalantine showed a good antioxidant activity when assayed by the DPPH radical spectrophotometric assay.

\section{Introduction}

Naphthopyranones belong to an uncommon class of natural compounds which occur mostly in fungi and include several important biological activities, like antifungal, phytotoxic, insecticidal, antitumour and gastroprotective ones (Hill, 1986). They originate either from the shikimate or from the acetate pathway leading to many variations of the basic skeleton. In the plant kingdom, these metabolites are restricted to few plant families (Hill, 1986), among these the Brazilian Paepalanthus species (Eriocaulaceae). The large majority of these plants are endemic to Brazil, in Minas Gerais State. They are popularly known as "everlasting plants" and are exported to Europe, Asia and North America due to the beauty of their flowers. Although these plants have only ornamental value and are not used in traditional medicine, the naphthopyranones present in these species (Vilegas et al., 1998) have shown a wide range of biological activities as antibiotic (Vilegas et al., 1990), cytotoxic and mutagenic (Varanda et al., 1997; Tavares et al., 1999). The phenolic structures of these naphthopyranones pose the question if they also have antioxidant activity. This is an important point, since nowadays it is well established that several diseases have their ethiologies based on the production and accumulation of free radicals and numerous natural compounds have been found useful as antioxidants (Polack and Morse, 1988). This knowledge has focused many studies on natural products as free radical scavengers, nothing is known, however, about the antioxidant activity of naphthopyranones. Further investigations on the biological activity of free naphthopyranones and its glycosides need to be developed and, in order to accomplish this, fast and efficient isolation of significative amounts of these constituents is essential.

The most common methodology for the isolation and purification of natural products generally involves adsorption techniques, such as isolation by open column chromatography over silica gel followed by purification using high performance liquid chromatography. However, there is a risk of irreversible adsorption, low recoveries of the compounds and even loss of the biological activity of the active principles.

We have previously used droplet counter-current chromatography for the isolation of isocoumarins from polar extracts of $P$. bromelioides (Santos et al., 1999). Despite the good resolution and reproducibility shown by this technique, separa- 
tions were time-consuming and the solvent consumption was quite high.

High speed counter-current chromatography (HSCCC) is a technique based on liquid-liquid partition of a solute between two imiscible solvents. Therefore HSCCC is considered a more gentle technique that eliminates the aforementioned problems. There is also no need for a tedious and laborious clean-up before the injection of crude extracts, and separations are very fast, taking only few hours to separate molecules from complex plant extracts. Many natural compounds were already efficiently isolated using HSCCC (Fischer et al., 1991; Foucault and Chevolot, 1998). Our group has been working with natural naphthopyranones and we have reported the isolation of naphthopyranone glycosides from Paepalanthus microphyllus (Santos and Vilegas, 2001), a species that includes only glycosides. In this work, we describe the use of HSCCC for separation and purification of the naphthopyranone aglycone $\mathbf{1}$ and its glycosides 2, 3 (Fig. 1) from a crude ethanolic extract of the capitula of Paepalanthus bromelioides in only one step. The isolated compounds were evaluated for their antioxidant activities.

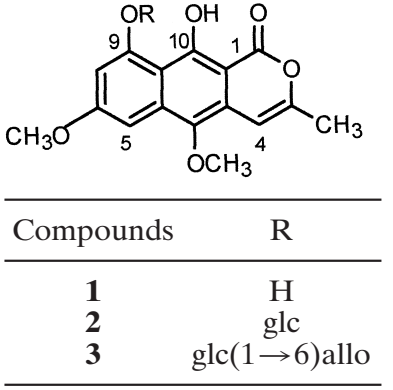

\section{Experimental}

General

All solvents used for HSCCC and HPLC were of analytical grade and obtained from Merck and Mallinckrodt Baker s. A., Brazil. The DPPH radical was purchased from Sigma. Commercial rutin was obtained from Merck and Ginkgo biloba extract (Art. Egb 761) was from Tebonin $40 \mathrm{mg}$ oral solution. Recordings were made by a UV-VIS spectrometer Shimadzu UV 2200.

\section{Preparation of crude sample and sample solution}

Capitula $(10 \mathrm{~g})$ of Paepalanthus bromelioides were collected at Serra do Cipó, Minas Gerais State, Brazil. The plant material was dried in an oven at $60^{\circ} \mathrm{C}$ for 1 week and powdered. The resulting material was macerated at room temperature sequentially with hexane, methylene chloride and ethanol during 1 week with each solvent. After filtration and evaporation of the solvents under reduced pressure we obtained approx. $1.0 \mathrm{~g}$ of each extract. A portion of the $70 \%$ ethanolic extract $(100 \mathrm{mg})$ was dissolved in $10 \mathrm{ml}$ of a mixture consisting of $10 \mathrm{ml}$ lower phase $+10 \mathrm{ml}$ upper phase of the solvent system water-ethanol-ethyl acetate-hexane (10:4:10:4, v/v/v/v) and centrifuged for $10 \mathrm{~min}$ at $1200 \mathrm{rpm}$.

\section{High-speed counter-current chromatography (HSCCC)}

The preparative HSCCC instrument employed was a P. C. Inc., Potomac, MD, USA. It was equipped with a triple multilayer coil of $1.68 \mathrm{~mm}$ i.d. polytetrafluoroethylene (PTFE) tubing of approx. $80 \mathrm{ml}$ and $240 \mathrm{ml}$ with a total capacity of $320 \mathrm{ml}$. The $\beta$ value varied from 0.50 at the internal terminal to 0.85 at the external terminal and the revolution radius was $10 \mathrm{~cm}(\beta=r / R$, where $r$ is the distance from the coil to the holder, and $R$, the revolution radius or the distance between the holder axis and the central shaft). The speed (varying between $0-1200 \mathrm{rpm}$. The flow rate $(2 \mathrm{ml} /$ min) was controlled with an FMI-50 QD-O SSY, BS/BS (Fluid Metering Inc., NY, USA) constantflow pump. The sample was injected with a P. C. Inc. injection module with a $20 \mathrm{ml}$ sample injection loop.

First, the coiled column was entirely filled with the stationary phase (lower phase). Then the apparatus was rotated forward at $800 \mathrm{rpm}$, while the mobile phase (upper phase) was pumped into the column in a tail to head $(\mathrm{T} \rightarrow \mathrm{H})$ direction at a flow-rate of $3.0 \mathrm{ml} / \mathrm{min}$. After the mobile phase front emerged and the hydrodynamic equilibrium was established in the column, about $10 \mathrm{ml}$ of the centrifuged sample solution containing $100 \mathrm{mg}$ of the crude extract was injected through the injection module at a flow-rate of $3.0 \mathrm{ml} / \mathrm{min}$. We obtained a total of 140 fractions of $10 \mathrm{ml}$ each with a Redifrac automated fraction collector (Pharmacia, 
Sweden), in approximately $7 \mathrm{~h}$. Rotation was stopped in fraction 140 and the washoff collected in $50 \mathrm{ml}$ fractions.

\section{Preparation of two-phase solvent system}

The solvent system composed of water-ethanolethyl acetate-hexance (10:4:10:4, v/v/v/v) was thoroughly equilibrated overnight in a separatory funnel at room temperature and the two phases separated and degassed shortly before use.

\section{Analyses of the compounds by TLC and HPLC}

The crude sample and fractions were analyzed using silica gel thin-layer chromatography (TLC) plates on glass $20 \times 20 \mathrm{~cm}$, Aldrich) developed with a solvent mixture composed of water-ethanolethyl acetate-hexane (10:4:10:4, v/v/v/v, upper layer). The spots on the TLC plates were observed under ultraviolet lamp (254 nm). Fractions of similar retention factors $\left(R_{F}\right)$ were combined and weighed.

Representative fractions were analysed using a Varian, ProStar HPLC system equipped with a RP-18 column (250 x 4.6 mm I. D., 8 um, Microsorb-MV $\left.{ }^{\mathrm{TM}}\right)$. The mobile phase used water/methanol 25:75 (v:v) at a flow-rate of $1.0 \mathrm{ml} / \mathrm{min}$, and the effluent was monitored using a ProStar 330 photodiode-array ultra-violet (PDA-UV, CA, USA) detector at $273 \mathrm{~nm}$.

\section{Structural identification of the compounds}

Nuclear magnetic resonance (NMR) spectra in $\mathrm{CD}_{3} \mathrm{OD}$ (compounds $\mathbf{1 - 3}$ ) were obtained using a Bruker spectrometer, operating at $200 \mathrm{MHz}$ for ${ }^{1} \mathrm{H}$ and $50 \mathrm{MHz}$ for ${ }^{13} \mathrm{C}$.

Electrospray mass spectra (ES-MS) were performed with a Fisons VG Platform instrument in a positive mode $(100 \mathrm{~V})$ to compounds $\mathbf{1 - 3}$. The samples were dissolved in methanol and injected directly into the mass spectrometer through a Rheodyne injector. Acetonitrile was used as the carrier solvent and nitrogen gas was used both as a drying gas and for nebulization.

\section{DPPH photometric assay}

Sample stock solutions $(1.0 \mathrm{mg} / \mathrm{ml})$ were diluted to final concentrations of $250,125,50,25,10$ and $5 \mu \mathrm{g} / \mathrm{ml}$, in ethanol. One $\mathrm{ml}$ of a $0.3 \mathrm{~mm} \mathrm{DPPH}$ ethanolic solution was added to $2.5 \mathrm{ml}$ of sample solutions of different concentrations, and allowed to react at room temperature. After 30 minutes the absorbance values were measured at $518 \mathrm{~nm}$ and converted into percentage of antioxidant activity (AA) using the following formula: $\mathbf{A} \mathbf{A} \%=$ 100 - [ [ (ABS SAMple $\left._{\text {- }} \mathbf{A B S}_{\text {BLANK }}\right) \times 100$ ]/ $\left.\mathbf{A B S}_{\text {Control }}\right\}$. Ethanol $(1.0 \mathrm{ml})$ plus compound solution $(2.5 \mathrm{ml})$ was used for blank. DPPH solution $(1.0 \mathrm{ml} ; 0.3 \mathrm{~mm})$ plus ethanol $(2.5 \mathrm{ml})$ was used for negative control. The positive controls were those using the standard solutions. The EC50 values were calculated by linear regression of plots where the abscissa represented the concentration of tested compounds and the ordinate the average percent of antioxidant activity from three separate tests (Mensor et al., 2001).

\section{Results}

A suitable solvent system for the separation of the naphthopyranones $\mathbf{1 - 3}$ was chosen by TLC to estimate the distribution of a small amount of sample between the two immiscible phases (Conway, 1990; Conway and Petroski, 1995). The solvent system water-ethanol-ethyl acetate-hexane was selected for its usefulness to separate medium polarity compounds. The ratios of hexane and ethyl acetate in this system [water-ethanol-ethyl acetate-hexane (10:4:10:4, v/v/v/v)] were balanced to give partition coefficient of approx. $\mathrm{K}^{\prime}-1$ for compounds of major interest. The retention of the stationary phase for this system in the HSCCC was $80 \%$. The upper layer of this mixture has shown good chromatographic resolution, with retention factors $\left(R_{F}\right)$ ranging from $0.2-0.9$. The ratio ethyl acetate/hexane (10:4) in this system indicates the rather high polarity of the compounds of $P$. bromelioides. The mixture also produced equal volumes of each phase, thus minimizing the problem of solvent waste. Since this mixture is composed of relatively volatile solvents, it also represents an advantage, because the collected compounds should undergo biological evaluation, which requires samples without traces of organic solvents.

Fig. 2 shows the HPLC-DAD analysis monitored at $273 \mathrm{~nm}$ of the original crude ethanolic extract of $P$. bromelioides. Peaks with retention times $3.3 \mathrm{~min}, 4.4 \mathrm{~min}$, and $5.5 \mathrm{~min}$ presented bands at $280 \mathrm{~nm}$ and $390 \mathrm{~nm}$ (Fig. 3), typical of naphthopyr- 


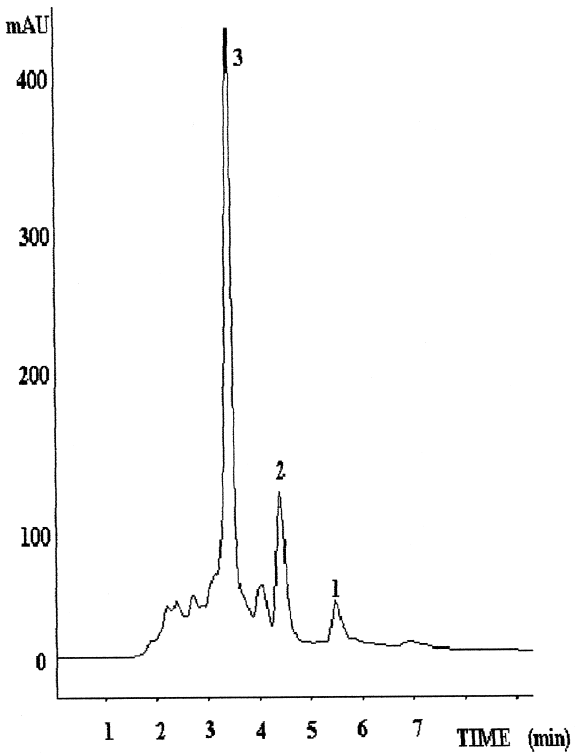

Fig. 2. HPLC separation of the crude extract of P. bromelioides. Experimental conditions: apparatus: Varian ProStar HPLC system equipped with a RP-18 column $(250 \times 4.6 \mathrm{~mm}$ I. D., $8 \mu \mathrm{m})$; mobile phase: water-methanol 25:75; flow rate $1.0 \mathrm{ml} / \mathrm{min}$; PDA-UV detection: $273 \mathrm{~nm}$.

anone derivatives $\mathbf{1 - 3}$ [2,3]. Identification of each peak was achieved by the co-injection of the extract together with the isolated compound and with authentic samples of compounds 1-3 from a collection of our laboratory (Vilegas et al., 1990; Vilegas et al., 1998).

Table I shows the results of the preparative HSCCC separation of compounds $\mathbf{1 - 3}$ from $P$. bromelioides. The identity and purity of the isolated compounds were checked by HPLC-DAD with authentic standards. Besides, the ${ }^{1} \mathrm{H}$ NMR spectra and ES-MS spectra of 1-3 were also recorded, showing identity with those previously reported (Vilegas et al., 1990; Vilegas et al., 1998).

The separation of the compounds was performed in one step in only $7 \mathrm{~h}$. With the upper

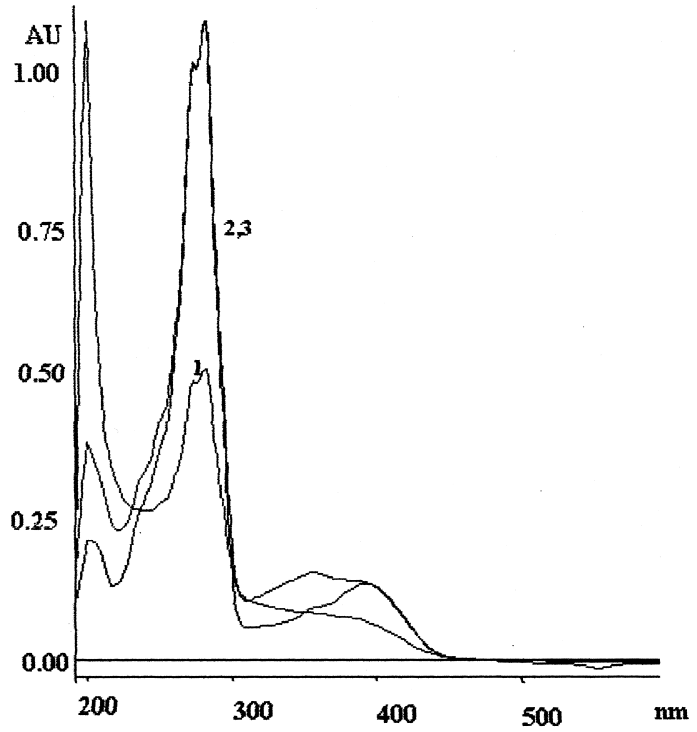

Fig. 3. UV spectra from the photodiode-array signals of the naphthopyranones 1-3 from P. bromelioides; PDAUV detection with absorbance monitored in the range $190-600 \mathrm{~nm}$.

layer as mobile phase, elution was dependent on the number of sugars attached to the aromatic nucleus, in reversed order to that observed in the HPLC analyses. Paepalantine, 1, was eluted almost with the solvent front $(\mathrm{K}=0)$, showing its high affinity for the upper phase of the solvent system used. The monoglucosylated derivative 2 (paepalantine-9-O- $\beta$-D-glucopyranoside) eluted after approx. $3.0 \mathrm{~h}$, whereas the more polar compound 3 (paepalantine-9-O- $\beta$-D-allopyranosyl- $(1 \rightarrow 6)-\mathrm{O}-\beta$ D-glucopyranoside) eluted after $6.5 \mathrm{~h}$.

Since naphthopyranones 1-3 were obtained with good degree of purity, the three compounds were directly submitted to the evaluation of their antioxidant activities by the DPPH radical spectrophotometric test (Table I).

Our results show that $\mathbf{1}$ is a stronger antioxidant than the other two glycosylated isocoumarins, with

Table I. Compounds isolated from $P$. bromelioides by HSCCC and their $\mathrm{EC}_{50}$ values $(\mu \mathrm{g} / \mathrm{ml})$ for antioxidant activity by DPPH spectrophotometric assay. (\%) Yield based on the crude extract injected.

\begin{tabular}{lccccr}
\hline Compound & Fractions & Yield $[\mathrm{mg}]$ & Purity & $\%$ Yield & $\mathrm{EC}_{50}{ }^{\mathrm{a}} \pm \mathrm{SD}$ \\
\hline $\mathbf{1}$ & $1-10$ & 5 & $92 \%$ & 5 & $18.4 \pm 0.4$ \\
$\mathbf{2}$ & $50-60$ & 9 & $97 \%$ & 9 & $274.3 \pm 1.7$ \\
$\mathbf{3}$ & $110-130$ & 18 & $96 \%$ & 18 & $280.0 \pm 1.8$ \\
\hline
\end{tabular}

a Rutin was used as standard $\left(\mathrm{EC}^{50}=14.16 \pm .20\right)$. 
an $\mathrm{EC}_{50}$ value similar to that of rutin (Table I), a flavonoid with recognized high antioxidant activity. Literature reports that the antioxidant activity of phenolic compounds and specially catechins is partly due to the capacity of the $3^{\prime}, 4^{\prime}$ ortho-positioned hydroxyl groups to chelate with metal ions like cupric ions (Mayer et al., 1998; Van Acker et al., 1996; Miller et al., 1996), thus preventing the oxidation of the low-density lipoprotein (LDL). The two free hydroxyls at position 9 and 10 and the carbonyl group of compound $\mathbf{1}$ offer possible sites to chelate with metal ions. Compounds $\mathbf{2}$ and $\mathbf{3}$ possess a free hydroxyl group only at position 10 , and have shown a lower antioxidant activity. Therefore, it seems that the number and position of available hydroxyl groups, besides size and disposition of functional groups in the compounds

Conway, W. D. (1990), Countercurrent Chromatography - Apparatus, Theory and Applications. VCH, New York.

Conway, W. D.d and Petroski, R. J. (eds.) (1995), Modern Countercurrent Chromatography. American Chemical Society, Washington DC.

Fischer N., Weinreich B., Nitz S. and Drawert F. J. (1991), Applications of high-speed countercurrent chromatography for the separation and isolation of natural products. J. Chromatogr. A 538, 193-202.

Foucault A. P. and Chevolot L. (1998), Countercurrent chromatography: instrumentation, solvent selctionand some recent applications to natural products purification. J. Chromatogr. A 808, 3-22.

Hill R. A. (1986), Naturally occurring isocoumarins. Fortsch. Chem. Org. Naturst. 49, 1-78.

Mayer A. S., Heinonen M. and Frankel E. N. (1998), Antioxidant interactions of catechin, cyanidin, caffeic acid, quercetin, and ellagic acid on human LDL oxidation. Food Chem. 61, 71-75.

Mensor L. L., Menezes F. S., Leitão G. G., Reis A. S., Santos T. C., Coube C. S. and Leitão S. G. (2001), Screening of Brazilian plant extracts for antioxidant activity by the use of DPPH free radical method. Phytother. Res. 15, 127-130.

Miller N. J., Castelluccio C., Tijburg L. and Rice-Evans C. (1996), The antioxidant properties of theaflavins and their gallate esters - radical scavengers or metal chelators? FEBS Lett. 392, 40-44.

Polack R. L. and Morse D. R. (1988), Free radicals and antioxidants: relation to chronic diseases and aging. Int. J. Psychosom. 1-4, 43-45. analysed are important features for reduction of DPPH radical.

\section{Conclusion}

Our studies have shown that HSCCC is a simple, quick and useful tool to isolate natural naphthopyranones with potent antioxidant activity in semi-preparative scale in good degree of purity. The low solvent consumption and the easy sample preparation also allow the process to be repeated several times in order to obtain larger amounts of pure compounds.

\section{Acknowledgements}

We thank FAPESP for funding and CNPq for a grant to W. V.

Santos L. C., Andrade F. D. P., Vasconcelos E. C., Coelho R. G., Dokkedal A. L., Gardcia A. C. L., Sano P. T. and Vilegas W. (1999), Separation of flavonoids and naphthopyranones from Brazilian Paepalanthus species by droplet counter-current chromatography. Rev. Bras. Pl. Med. 2, 43-47.

Santos L. C. and Vilegas W. (2001), Preparative separation of the naphthopyranone glycosides by high-speed counter-current chromatography. J. Chromatogr. A 915, 259-263.

Tavares D. C., Varanda E. A., Andrade F. D. P., Vilegas W. and Takahashi C. S. (1999), Evaluation of the genotoxic potential of the isocoumarin Paepalantine in in vivo and in vitro mammalian systems. J. Ethnopharmacol. 68, $115-120$.

Van Acker S. A. B. E., Van den Berg D. J., Tromp M. N. J. L., Griffioen E. H., Van Bennekm W. P., Van der Jijgh W. J. F. and Bast A. (1996), Structural aspects of antioxidant acitivity of flavonoids. Free Radical Biol. Med. 20, 331-342.

Varanda E. A., Raddi M. S. G., Dias F. L. P., Araujo M. C. S., Gibran S. C. A., Takahashi C. S. and Vilegas W. (1997), Mutagenic and cytotoxic activity of an isocoumarin (Paepalantine) isolated from Paepalanthus vellozioides. Teratog. Carcinog. Mutagen. 17, 85-95.

Vilegas W., Roque N. F., Salatino A., Giesbrecht A. M. and Davino S. (1990), Isocoumarin from Paepalanthus bromelioides. Phytochemistry 29, 2299-2301.

Vilegas W., Santos L. C., Alécio A. C., Piacente S., Pizza C., DePauw E. and Sano P. T. (1998), Naphthopyranone glycosides from Paepalanthus bromelioides. Phytochemistry 49, 207-210. 